\title{
Myocardial scar surface area identified by LGE MRI is an independent predictor of mortality in post- infarction patients
}

\author{
Qian Tao ${ }^{1 *}$, Sebastiaan R Piers ${ }^{2}$, Hildo J Lamb ${ }^{1}$, Katja Zeppenfeld ${ }^{2}$, Rob J van der Geest ${ }^{1}$ \\ From 18th Annual SCMR Scientific Sessions \\ Nice, France. 4-7 February 2015
}

\section{Background}

Recent research has shown that the size of myocardial gray zone (a mixture of normal and infarcted tissue) identified from late gadolinium enhanced (LGE) MRI is an independent predictor of adverse cardiac events in post-infarction patients. However, definition of myocardial gray zone in LGE images (e.g. using the N-STD method) remains difficult for varying MR protocols and qualities, lacks histological validation, and may lead to conflicting conclusions. We sought to establish a novel predictive scar parameter independent of gray zone definition.

\section{Methods}

Eighty-six patients (age $64 \pm 10$ ) with prior myocardial infarction underwent a cardiac MRI study prior to ICD implantation. The MRI study included cine-MRI for evaluation of cardiac function e.g. left ventricular ejection fraction (LVEF), and LGE-MRI for assessment of myocardial infarction size and morphology. The total myocardial scar and gray zone sizes were estimated from scar regions identified by the full-width-half- maxima (FWHM) method with $35 \%$ and $50 \%$ threshold, respectively. The total myocardial scar surface areas were computed based on 3D reconstruction of the identified myocardial scar. Patients were followed at our institute.

\section{Results}

During a median follow-up of 45 months, interquartile 34-58 months, 22 (26\%) patients died. Univariate Cox proportional hazard analysis showed that the total scar size, gray zone size, and total scar surface area were all predictors of patient mortality, with a Cox hazard ratio $\mathrm{HR}=1.16 / 10 \mathrm{~g}(\mathrm{p}=0.01)$ for total scar size, $\mathrm{HR}=1.55 / 10 \mathrm{~g}$ $(\mathrm{p}=0.02)$ for gray zone size, and $H R=1.59 / 100 \mathrm{~cm}^{2}$ $(\mathrm{p}=0.003)$ for total scar surface area. However, after correction for LVEF, multivariate Cox proportional hazard analysis showed that only the total scar surface area remained predictive of all-cause mortality, with $\mathrm{HR}=1.75 / 100 \mathrm{~cm}^{2}, \mathrm{p}=0.01$. Table 1 reports the scar sizes, surface areas, HR, and $p$ values. Kaplan-Meier plot of survival functions differentiated by the proposed total scar surface area parameter was presented in Figure 1.

Table 1 The results of univariate and multivariate Cox proportional hazard analysis for scar features identified from LGE-MRI.

\begin{tabular}{cccccccc}
\hline & \multirow{2}{*}{ Median (IQR) } & \multicolumn{2}{c}{ Univariate Cox hazard analysis } & \multicolumn{2}{c}{ Multivariate Cox hazard analysis (corrected for LVEF) } \\
\cline { 3 - 8 } & & $\mathrm{HR}$ & $95 \% \mathrm{Cl}$ & $\mathrm{P}$ value & $\mathrm{HR}$ & $95 \% \mathrm{Cl}$ & $\mathrm{P}$ value \\
\hline Total scar size & $56 \mathrm{~g}(38-77 \mathrm{~g})$ & $1.16 / 10 \mathrm{~g}$ & $1.03-1.31$ & $0.01^{*}$ & $1.18 / 10 \mathrm{~g}$ & $0.99-1.41$ & 0.06 \\
\hline Gray zone size & $14 \mathrm{~g}(9-23 \mathrm{~g})$ & $1.55 / 10 \mathrm{~g}$ & $1.06-2.27$ & $0.02^{*}$ & $1.51 / 10 \mathrm{~g}$ & $0.94-2.44$ & 0.08 \\
\hline Total scar surface area & $245 \mathrm{~cm} 2(178-334 \mathrm{~cm} 2)$ & $1.59 / 100 \mathrm{~cm} 2$ & $1.17-2.15$ & $0.003^{*}$ & $1.75 / 100 \mathrm{~cm} 2$ & $1.13-2.71$ & $0.01^{*}$ \\
\hline
\end{tabular}

'Department of Radiology, Leiden University Medical Center, Leiden,

Netherlands

Full list of author information is available at the end of the article 


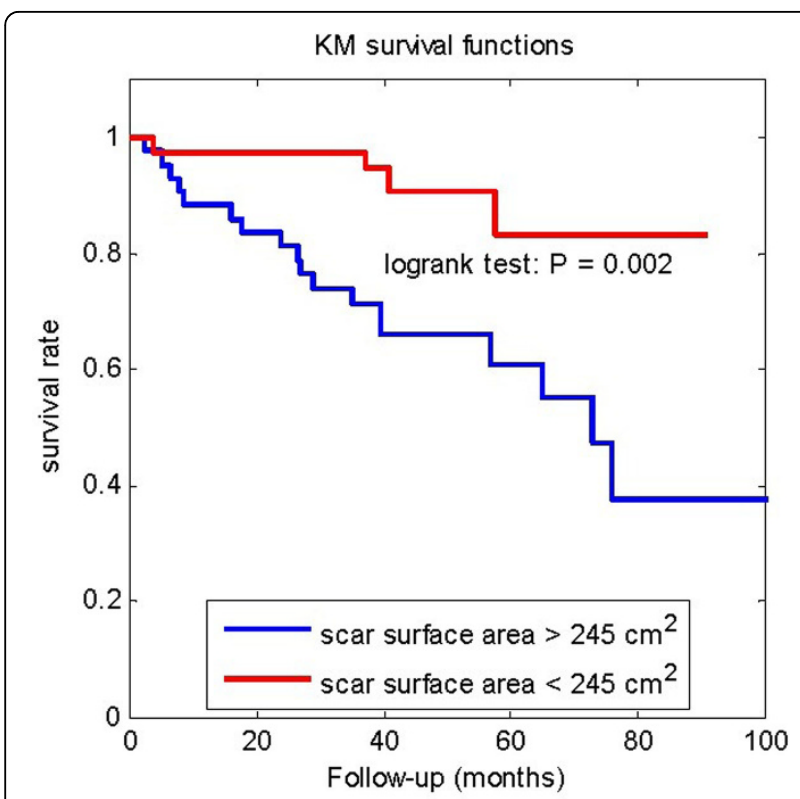

Figure 1 The comparison of estimated Kaplan-Meier survival functions with different scar surface areas. The threshold $245 \mathrm{~cm}^{2}$ is the median value of scar surface areas. The $P$ values of logrank test is also reported.

\section{Conclusions}

Total myocardial scar surface area identified from LGE MRI is a predictor of all-course mortality in post-infarction patients, independent of LVEF. The method used the histologically validated FWHM method to quantify the scar, while avoiding gray zone definition. The study highlights the potential of scar morphology analysis from LGE-MRI, beyond conventional scar size parameters.

\section{Funding}

Dutch Technology Foundation (STW project no.12899).

\section{Authors' details}

'Department of Radiology, Leiden University Medical Center, Leiden, Netherlands. ${ }^{2}$ Department of Cardiology, Leiden University Medical Center, Leiden, Netherlands.

Published: 3 February 2015

\section{doi:10.1186/1532-429X-17-S1-P46}

Cite this article as: Tao et al: Myocardial scar surface area identified by

LGE MRI is an independent predictor of mortality in post-infarction

patients. Journal of Cardiovascular Magnetic Resonance 2015 17(Suppl 1):P46.
Submit your next manuscript to BioMed Central and take full advantage of:

- Convenient online submission

- Thorough peer review

- No space constraints or color figure charges

- Immediate publication on acceptance

- Inclusion in PubMed, CAS, Scopus and Google Scholar

- Research which is freely available for redistribution

Submit your manuscript at www.biomedcentral.com/submit 